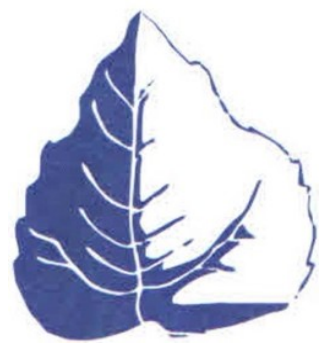

УДК 522.94

\section{ЭКОЛОГИЯ (ПО ОТРАСЛЯМ) ECOLOGY (ITS BRUNCHES)}

Исследование ошибок при проведении судебно-экологической экспертизы

Овчинникова Н. Г., Глазков А. С., Водолазская Т. С.

Донской государственный технический университет (Ростов-на-Дону, Российская Федерация)

При совершении экологических преступлений в первую очередь выясняются обстоятельства их совершения, главную роль в этом играет судебно-экологическая экспертиза.

Экологическая экспертиза представляет собой определение соответствия документов, которые устанавливают намечаемую хозяйственную и иную деятельность объекта экологической экспертизы, экологическим требованиям. Экологические требования устанавливаются техническими регламентами и законодательством в области охраны окружающей среды.

В ходе досудебного и судебного производства по уголовным, гражданским и административным делам необходим опыт, специальные навыки и знания, в первую очередь, в области экологии, далее - биологии, почвоведения и других естественных наук.

Ключевые слова: экологическая экспертиза, технический регламент, охрана окружающей среды, экология.

Для цитирования: Овчинникова Н. Г. Исследование ошибок при проведении судебно-экологической экспертизы / Н. Г. Овчинникова, А. С. Глазков, Т. С. Водолазская // Экономика и экология территориальных образований. - 2021. - Т. 5, № 4. - С. 59-66. https://doi.org/10.23947/2413-1474-2021-5-4-59-66

\title{
Investigation of errors during forensic environmental examination
}

Ovchinnikova N. G., Glazkov A. S., Vodolazskaya T. S.

Don State Technical University (Rostov-on-Don, Russian Federation)

When committing environmental crimes, first of all, the circumstances of the commission of the crime are clarified, the main role in this is played by forensic environmental expertise.

Environmental expertise is the establishment of compliance of documents and documentation that establish the planned economic and other activities of the object of environmental expertise with environmental requirements. Environmental requirements are established by technical regulations and legislation in the field of environmental protection.

In the course of pre-trial and judicial proceedings in criminal, civil and administrative cases, experience and special skills and knowledge are needed primarily in the field of ecology, then in the fields of biology, soil science and other natural sciences.

Keywords: environmental expertise, technical regulations, environmental protection, ecology. 
For citation: N. G. Ovchinnikova, A. S. Glazkov, T. S. Vodolazskaya. Investigation of errors during forensic environmental examination. Economy and ecology of territorial formations, 2021, vol. 5, no 4, pp. 59-66. https://doi.org/10.23947/2413-1474-2021-5-4-59-66

Введение. Говоря о принципах, лежащих в основе судебно-экологической экспертизы, стоит отметить, что они являются первостепенными и их несоблюдение приводит к типичным ошибкам.

Одним из таких принципов является комплексность мероприятий по выявлению и уточнению причин возникновения экологических преступлений на различных территориях [1]. Зачастую это несоблюдение рекомендаций, указанных в документации, прилагаемой к реализации объекта хозяйственной или иной деятельности.

Ещё один принцип - обязательность проведения государственной экологической экспертизы до принятия решения о реализации объекта экологической экспертизы.

Цель данной статьи - анализ ошибок, допускаемых специалистами при проведении судебно-экологической экспертизы, выработка рекомендаций для повышения качества проводимых исследований.

Основная часть. Изучив ошибки, допускаемые при выполнении судебно-экологической экспертизы, можно сделать следующий вывод:

- прежде чем приступать к судебно-экологической экспертизе, следует внимательно изучить все документы и техническую документацию, прилагаемые к объекту экологической экспертизы, на предмет его экологической безопасности;

— затем следует убедиться в достоверности и полноте информации, представленной на экологическую экспертизу;

— любые решения и заключения по результатам экологической экспертизы должны быть научно обоснованы, объективны и законно подтверждены.

Проведение судебно-экологической экспертизы регламентируется УПК РФ, Федеральным законом «О государственной судебно-экспертной деятельности в Российской Федерации».

Авторы статьи дополнительно проанализировали работы по совершенствованию и развитию территорий [2-10].

Основными задачами судебно-экологической экспертизы являются:

- определение источника вредного антропогенного воздействия, его вид и местоположение;

- изучение характеристик вредного антропогенного воздействия на окружающую среду;

— определение механизма негативного антропогенного воздействия на окружающую среду;

- установление дальнейшего развития такого воздействия, любых условий и обстоятельств, которые могут способствовать усилению вредного влияния на окружающую среду;

- выявление масштабов негативного влияния на окружающую среду;

- установление действий, в ходе которых было нарушено природоохранное законодательство, изучение технической документации по условиям эксплуатации особо опасных объектов по влиянию на окружающую среду. 
Поскольку судебно-экологическая экспертиза заключается ещё и в практическом исследовании антропогенных воздействий на конкретные объекты окружающей среды, то основным инструментом в предоставлении доказательств преступления являются лабораторные исследования проб атмосферного воздуха, воды, почвы, взятых в месте выбросов, образцы флоры и фауны, пораженные вредными воздействиями [11-12].

Анализ некоторых материалов судебно-экологической экспертизы позволил выявить ряд содержавшихся в них ошибок:

- в заключении отсутствовали сведения о материалах, взятых в местах выбросов;

— экспертиза проводилась по косвенным доказательствам, таким как фотографии и документы, имеющиеся в деле, без выезда на загрязненную местность;

- была нарушена конкретная методика проведения экспертизы.

В большинстве случаев экспертные ошибки возникают из-за недобросовестной подготовки следователя к назначению экспертизы. Самая распространенная ошибка следователей - это постановка неопределенных вопросов экологическому эксперту. Нередко следователи ставят перед экспертами вопросы юридического характера, отвечать на которые эксперт-эколог не обязан, поскольку это не в его компетенции, зачастую такие вопросы приводят экспертов к совершению ошибок.

Экспертные ошибки возникают также в связи с неправильным отбором следователем объектов для исследования.

Проанализировав приведенные выше ошибки, можно сделать вывод, что для проведения качественной судебно-экологической экспертизы нужно:

- позаботиться об обеспечении сотрудников следствия справочной литературой об особенностях назначения судебно-экологической экспертизы;

- экспертам и специалистам, выполняющим исследования объектов окружающей среды, подвергшихся экологическим преступлениям, необходимо постоянно совершенствовать свои навыки и повышать уровень знаний.

Одним из примеров экспертной ошибки при проведении судебно-экологической экспертизы служит уголовное дело, связанное с обвинениями начальника подразделения «Майкопское лесничество» управления лесами Республики Адыгея, который относился недобросовестно к исполнению своих должностных обязанностей. Обвинения выдвинуты по причине нарушения закона об охраняемых территориях и нанесения государству крупного ущерба.

При проведении предварительного расследования было выявлено, что начальник подразделения согласовал предпринимателю технологическую карту на разработку лесосеки на деляне, местонахождение которой было в пределах охраняемой природной территории памятника природы республиканского значения «Верховья рек Пшехи и Пшехашки». Памятник был включен в список Всемирного природного наследия ЮНЕСКО. Кроме того, предпринимателю был разрешен вывоз поваленной древесины. Экспертами было установлено, что вследствие трелевки древесины был причинен невосполнимый ущерб почвенному слою, то есть было уничтожено более 8,5 тыс. кв. м. почвенного покрова, а общая сумма причиненного ущерба составила более 235 миллионов рублей.

В зале суда была назначена судебно-экологическая экспертиза в ФГУ «НИИ Горлесэкол» в городе Сочи. Вследствие этой судебно-экологической экспертизы был получен совершенно иной результат, а именно: ущерб природе не был нанесен, трелевка древесины была выполнена без каких-либо нарушений. Государственный обвинитель запросил повторную экспертизу, по её результатам было установлено, что эксперты провели исследование только по 
документам в деле и предоставленным фотографиям. Таким образом, эксперты, не выходя из кабинета, совершили большую ошибку, что повлекло за собой уйму потраченного впустую времени и сил со стороны обвиняемого (практика ВС Республики Адыгея за 2011 год, дело № 22-396).

Судебно-экологическая экспертиза занимает пятое место среди других видов экспертиз, но она играет важную роль в защите природы (рис. 1).

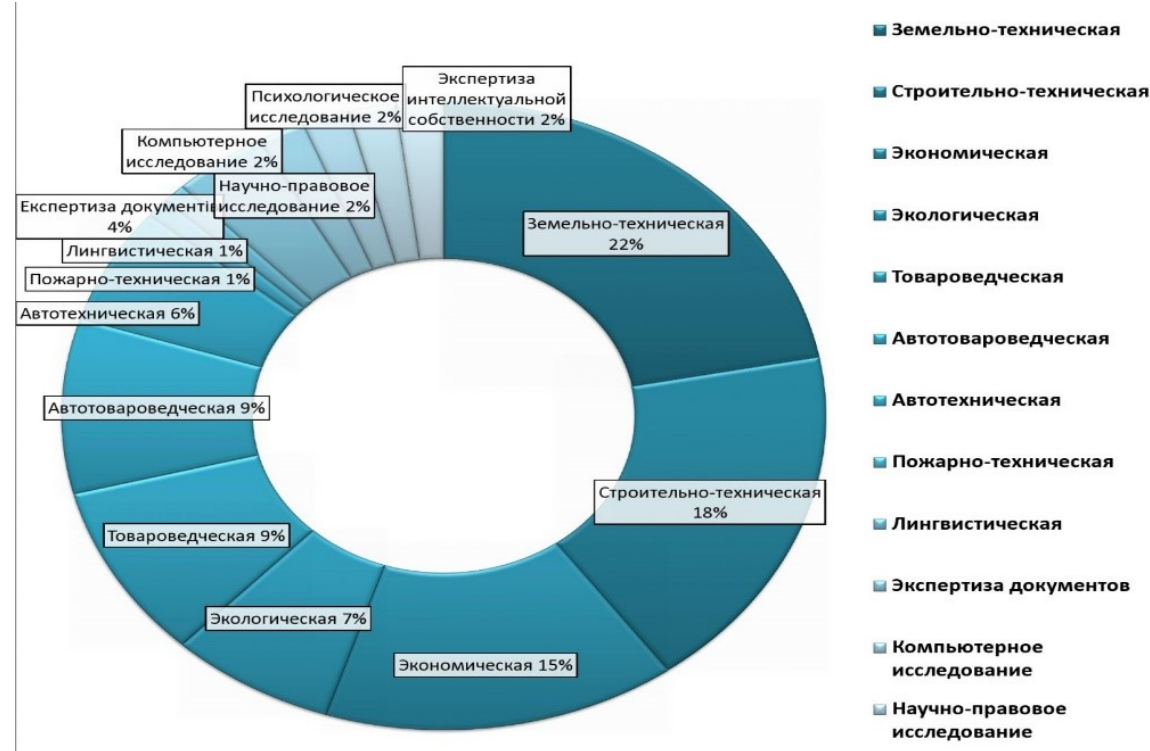

Рис. 1. Количество проведенных экспертиз по определению суда

Из судебной практики следует, что за последние 10 лет по статьям 246-262 за экологические преступления 99\% дел возбуждается лишь по пяти статьям. Наиболее часто привлекаются к ответственности граждане, совершившие преступления, предусмотренные статьей 256 (ч. 1 и ч. 3) «Незаконная добыча (вылов) водных биологических ресурсов», статьей 260 (ч. 1, ч. 2, ч. 3) «Незаконная рубка лесных насаждений».

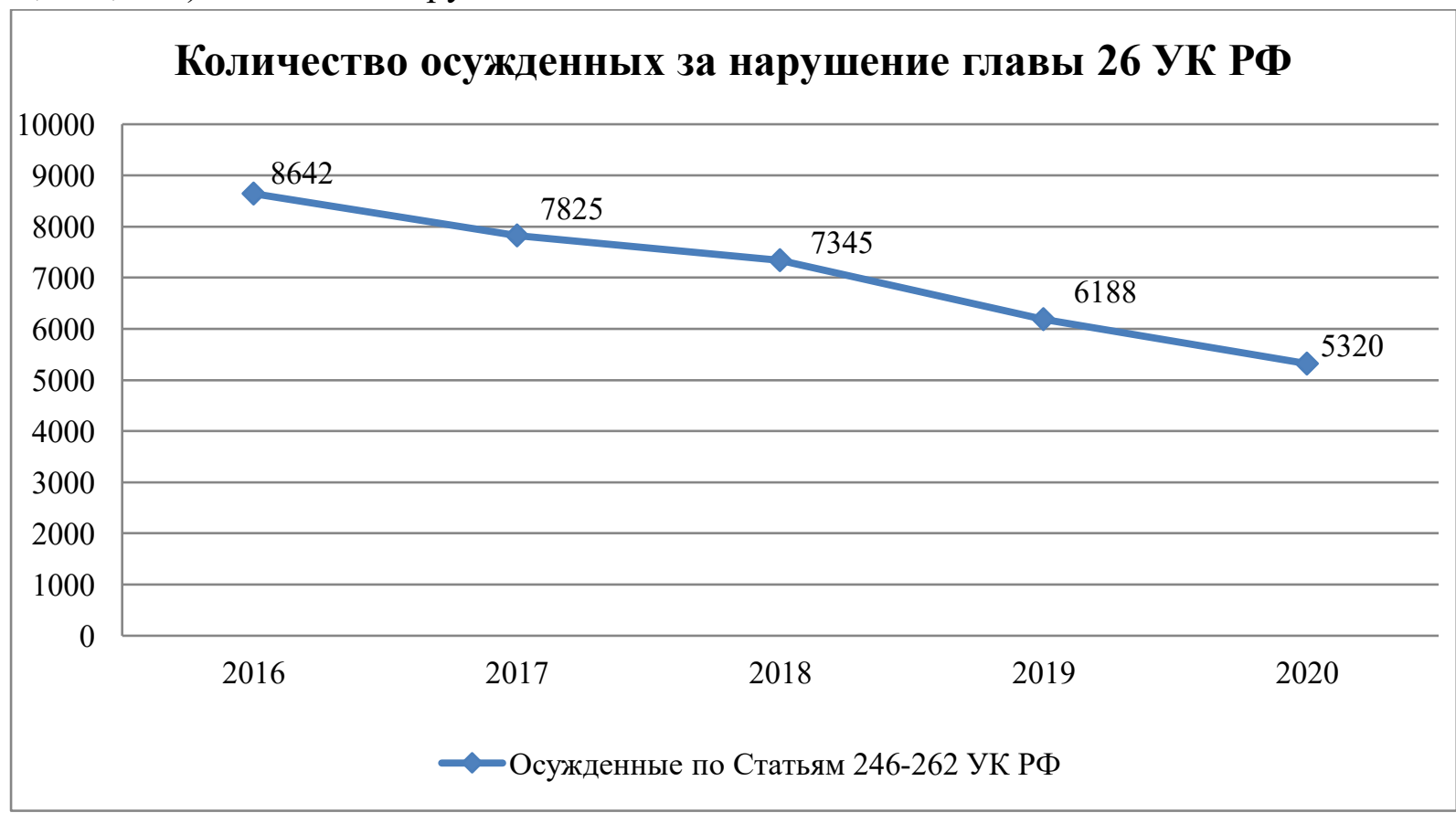

Рис. 1. Количество осужденных по статьям 246-262 УК РФ 
Построив график, отображающий количество осужденных по «экологическим» статьям, можно убедиться, что из года в год их становится все меньше и меньше.

Дело № A43-7264/2008 касается компенсации вреда, причиненного окружающей среде. Причиной возбуждения такого дела стал прорыв магистрали нефтепровода, который произошел в 2007 году около села Слободское Кстовского района Нижегородской области. Вследствие прорыва топливо попало в местную реку Шава. Эта река питала множество озер, была между ними связующим звеном. Судебно-экологической экспертизой было установлено, что флора и фауна озер уничтожена. Поэтому местный рыбхоз подал в суд иск на ОАО «СреднеВолжский Транснефтепродукт».

Эксперты установили сумму причиненного ущерба в размере миллиарда рублей. Суд первой инстанции иск удовлетворил. Но спустя три года дело получило новый оборот. Оно возвращается на пересмотр, а причиной стало уголовное дело, которое было возбужденно в отношении экспертов, определивших сумму нанесенного ущерба.

В рамках расследования уголовного дела эксперты признались, что осознанно дали ложное заключение. За время, пока велось уголовное дело в отношении экспертов, ОАО «Средне-Волжский Транснефтепродукт» стало частью Транснефти, и уже Транснефть обратилась с заявлением о пересмотре судебных актов по вновь открывшимся обстоятельствам. Дело было пересмотрено, суд назначил повторную экспертизу, согласно которой сумма причиненного ущерба стала равной уже 85 миллионам рублей. Но это не все, суд также принял решение обязать рыбхоз возместить Транснефти 51 миллион рублей, что обрекло рыбхоз на банкротство.

Самое ужасное в этом деле то, что озёра так и не были восстановлены, на них до сих пор плавают дизельные пятна. Продолжением этой истории стало обращение конкурсного управляющего рыбхоза в суд с иском к экспертной компании (Эксперт Союз) с требованием о взыскании убытков за недостоверное заключение.

Другим примером, показывающим важность полного изучения объекта судебного конфликта и необходимость знания всех подводных камней законодательства, является судебное дело ООО «НовСвин».

Общество обратилось в суд с заявлением о признании недействительным предписание об устранении нарушений природоохранных требований, выдвинутых Северо-Западным межрегиональным управлением службы по надзору в сфере природопользования.

К слову, сельхозпроизводитель имеет право на использование продуктов, образующихся в ходе жизнедеятельности животных, в собственных целях, конкретно в собственном производстве, не оформляя для этого лицензии.

Межрегиональное управление, опираясь на Федеральный классификационный каталог отходов, посчитала свежий свиной навоз отходами III класса опасности, в то время как ООО «НовСвин» комплексно обезвреживает указанные отходы в навозохранилище в течение 3-6 месяцев.

Также управление считает, что общество осуществляет деятельность, связанную с использованием данных отходов. В связи с вышеперечисленным суд удовлетворил заявленные требования о признании недействительным предписание межрегионального управления службы по надзору в сфере природопользования, исходя из установленного факта, что ООО «НовСвин» не ведет действий, которые бы подлежали лицензированию, поскольку навоз, производимый свиньями, используется в качестве удобрений на собственных полях и данные действия подтверждены внутренними документами ООО «НовСвин» (план-графики, 
инструкции и рабочие журналы). Также общество разработало техрегламент и техусловия, которые были официально зарегистрированы.

Таким образом, ООО «НовСвин» официально оформило навоз свиной как продукт органическое удобрение и использует его в своей производственной деятельности. Постановление АС СЗО от 09.06.2020 по делу № А44-4807/2019.

Ещё одно дело связано с предписанием, выданным ООО «Краснодар Водоканал» (далее - общество) Межрегиональноым управлением Федеральной службы по надзору в сфере природопользования по Краснодарскому краю и Республике Адыгея (далее - управление). Предписание было выдано по результатам проверки, в нем указывалось на необходимость вести учет обращения с отходом - осадком биологических очистных сооружений хозяйственнобытовой и смешанной канализации, который обществом в дальнейшем использовалось как органическое удобрение для сельскохозяйственного производства, на что ООО «Краснодар Водоканал» было выдано свидетельство о государственной регистрации пестицида.

Посчитав такое предписание недействительным, ООО «Краснодар Водоканал» обратилось в суд. Приняв во внимание регистрационные действия в отношении органического удобрения (иловых осадков), суд пришел к выводу, что иловые площадки не относятся к объектам размещения отходов, а сами осадки сточных вод не являются отходами, так как они обладают потребительскими свойствами, выступая сырьём для производства органических удобрений.

К слову, данное свидетельство о регистрации пестицида даёт разрешение на допуск к обороту на территории Российской Федерации производимого удобрения, подтверждая, что осадок сточных вод выступает сырьем для производства органических удобрений.

Также были принята во внимание и представленная технологическая документация, согласно которой органическое удобрение на основе сточных вод представляет собой продукт из сырья, которое обезврежено естественным путем, то есть из осадков сточных вод и подсушенных на иловых картах в течение нескольких лет. Вдобавок ко всему органическое удобрение изготавливалось согласно действующим нормативным требованиям.

Департаментом Федеральной службы по надзору в сфере природопользования по Центральному федеральному округу была проведена государственная экологическая экспертиза и представлен приказ об утверждении положительного заключения ГЭЭ по проекту технической документации для регистрации агрохимиката «Органическое удобрение на основе осадков сточных вод». Постановление АС СКО от 07.06.2020 по делу № А32-28802/2019.

На примере этого дела можно сделать вывод о том, что необходимо досконально анализировать всю техническую документацию организации и выданные разрешения на оборот тех или иных отходов деятельности организации.

Заключение. В заключение необходимо особо отметить, что для повышения качества проводимых судебно-экологических экспертиз следует организовать курсы по повышению квалификации экспертов, экспертам внимательно изучать все материалы дела, быть внимательным к мелочам, не пренебрегать выездом на место совершения преступления, следователям необходимо четко и ясно ставить задачи для экспертов и только в зоне их компетенции. Все это должно в конечном итоге способствовать дальнейшему развитию территории, повышению качества жизни населения [13-15].

\section{Библиографический список}

1. Медведков, Д. А. Комплексное и устойчивое развитие застроенной территории: опыт, проблемы и пути их решения / Д. А. Медведков, Н. Г. Овчинникова // Организационно- 
экономические проблемы регионального развития в современных условиях : материалы научно-практической конференции молодых ученых, аспирантов и студентов. - Симферополь, 2018. - С. 204-206.

2. Овчинникова, Н. Г. Социо-эколого-экономическое моделирование процессов управления земельными ресурсами в сфере сельскохозяйственного производства / Н. Г. Овчинникова // Terra Economicus. - 2011. - Т. 9, № 3-2. - С. 89-91.

3. Овчинникова, Н. Г. Разработка и принятие проектных решений по организации рационального использования земельных ресурсов / Н. Г. Овчинникова // Известия Ростовского государственного строительного университета. — 2011. — № 15. — С. 225-230.

4. Овчинникова, Н. Г. Оценка производственного потенциала сельскохозяйственных предприятий / Н. Г. Овчинникова, С. Н. Гончарова // Науковедение. - 2012. — № 3 (12). C. 112 .

5. Овчинникова, Н. Г. Ответственность кадастрового инженера в сфере земельно-имущественных отношений / Н. Г. Овчинникова, Е. С. Шумкова // Экономика и экология территориальных образований. - 2015. - № 3. - С. 36-39.

6. Овчинникова, Н. Г. Учетно-регистрационный процесс в системе управления земельными ресурсами / Н. Г. Овчинникова, Е. С. Шумкова // Экономика и экология территориальных образований. - 2016. - № 2. - С. 125-129.

7. Овчинникова, Н. Г. Государственный кадастровый учет как инструмент информационного обеспечения системы управления земельными ресурсами и развития земельного рынка / Н. Г. Овчинникова, А. И. Щиренко // Экономика и экология территориальных образований. - 2016. - № 2. - С. 67-71.

8. Овчинникова, Н. Г. Организация рационального использования земельных ресурсов при территориальном планировании муниципальных образований / Н. Г. Овчинникова, В. В. Шмакова // Экономика и экология территориальных образований. - 2017. — № 4. C. $80-90$.

9. Русских, А. В. Значимость документов территориального планирования муниципального образования для ведения ЕГРН / А. В. Русских, Н. Г. Овчинникова // Научные труды КубГТУ. — 2017. — № 4. - С. 285-289.

10. Алиева, Н. В. Функции управления земельными ресурсами в решении вопросов развития территорий субъекта Российской Федерации / Н. В. Алиева, Н. Г. Овчинникова // Вестник Южно-Российского государственного технического университета (Новочеркасского политехнического института). Серия: Социально-экономические науки. — 2017. — № 3. C. $79-83$.

11. Ovchinnikova N.G. Analysis of territorial planning and prospects for further development of urban districts and settlements in Rostov region // MATEC Web of Conferences. 2017. P. 01004.

12. Ovchinnikova N., Vodolazskaya T. Challenges and perspectives for rural development. E3S Web of Conferences. XIV International Scientific and Practical Conference "State and Prospects for the Development of Agribusiness - Interagromash 2021”. Rostov-on-Don, 2021. P. 06007.

13. Ovchinnikova N., Aliyeva N., Petrova I. Principles and methodological approaches to efficient use of land. E3S Web of Conferences. XIV International Scientific and Practical Conference "State and Prospects for the Development of Agribusiness - Interagromash 2021". Rostov-on-Don, 2021. P. 06008. 
14. Ovchinnikova N. Analysis of sustainable development of rural areas in Russia: results, challenges and solutions. E3S Web of Conferences. 8. "Innovative Technologies in Science and Education, ITSE 2020" 2020. P. 14002.

15. Ovchinnikova N., Batranyuk M., Zhidkova E., Lazebnaya Y., Timofeeva V. Main areas of land use in municipal entity B сборнике: E3S Web of Conferences. 8. Cep. "Innovative Technologies in Science and Education, ITSE 2020" 2020. P. 09004.

\section{Об авторах:}

Овчинникова Наталья Геннадьевна, доцент кафедры «Экономика природопользования и кадастра» Донского государственного технического университета (344003, РФ, г. Ростов-на-Дону, пл. Гагарина, 1), кандидат экономических наук, доцент, donong160875@yandex.ru

Глазков Андрей Сергеевич, магистрант кафедры «Экономика природопользования и кадастра» Донского государственного технического университета (344003, РФ, г. Ростов-наДону, пл. Гагарина, 1), mseone0@gmail.com

Водолазская Татьяна Сергеевна, магистрант кафедры «Экономика природопользования и кадастра» Донского государственного технического университета (344003, РФ, г. Ростов-на-Дону, пл. Гагарина, 1), 1chinaski1@gmail.com

\section{Authors:}

Ovchinnikova N. G. associate professor, the department of "Environmental Economics and Cadaster", Don State Technical University (1, Gagarina sq., Rostov-on-Don, RF, 344003), donong160875@yandex.ru

Glazkov A. S. Master's student, Department of Environmental Economics and Cadastre, Department of Magistracy, Don State Technical University (1, Gagarina sq., Rostov-on-Don, RF, 344003) mseone0@gmail.com

Vodolazskaya T. S. Master's student, Department of Environmental Economics and Cadastre, Department of Magistracy. Don State Technical University (1, Gagarina sq., Rostov-on-Don, RF, 344003) vodolazskaya.tanya@mail.ru 